\title{
Researching the Moral Experiences of Young Children: A Pilot Study
}

\author{
Nora Makansi and Franco Carnevale
}

\begin{abstract}
Nora Nader Makansi holds an undergraduate degree in dentistry. She completed her master's and doctoral studies in the Division of Oral Health and Society at McGill University's Faculty of Dentistry. Later, Nora joined the VOICE (Views On Interdisciplinary Childhood Ethics) project in January 2015 as a postdoctoral trainee working with Drs. Franco Carnevale and Mary Ellen Macdonald. Through her doctoral and postdoctoral training, Nora developed her research experience in qualitative and mixed methods research. She is currently a research associate and lecturer with the Faculty of Dentistry, McGill University. She is also involved as an instructor in the faculty's annual summer institute on innovative research methodologies. Email: nora.makansi@mcgill.ca
\end{abstract}

Franco A. Carnevale is a nurse, psychologist, and clinical ethicist. He completed his undergraduate nursing degree, three master's degrees (in nursing, education, and bioethics) and a doctorate in counselling psychology at McGill University. He also completed a master's degree in philosophy at Université de Sherbrooke and a second doctorate in moral philosophy at Université Laval. In addition, he completed graduate studies in health law, anthropology, and cultural psychiatry. Dr. Carnevale's primary research interests include a wide range of concerns in pediatric ethics. He is the founder and principal investigator for VOICE (Views On Interdisciplinary Childhood Ethics), a McGill-based international initiative to advance knowledge and practices relating to ethical concerns in childhood. Dr. Carnevale's current academic appointments (all at McGill University) include full professor, Ingram School of Nursing; associate member, Faculty of Medicine (Pediatrics); adjunct professor, Counselling Psychology; affiliate member, Biomedical Ethics Unit. His clinical appointments include co-chair of the Pediatric Ethics Committee, nursing advisor, and associate member of Pediatric Critical Care, all at Montreal Children's Hospital-McGill University Health Centre, as well as clinical ethicist for Child, Adolescent, and Family Services at the Douglas Mental Health University Institute and Clinical Ethics Consultant at Le Phare, Enfants et Familles (pediatric hospice and respite care).

The aim of this pilot study was to develop a research design and refine data collection and analysis methods to examine moral experiences of children in an education context. We piloted two data collection methods: participant observation and one-on-one interviews in preschool classrooms and with school-aged children, respectively. Our thematic analysis revealed how children coconstruct their daily experiences in this particular context; when and how they resist rules; and what moral experiences may look like in preschool interactions and how they may be understood and expressed by schoolaged children. We also discussed methodological reflections on rapport building and power dynamics within these research methods.

Key words: children; agency; moral agency; research methods; qualitative research
The epistemological standpoint from which we study the lives and experiences of children (defined here as legal minors) has shifted remarkably. Marked by the 1989 United Nation's Convention on the Rights of the Child, the "rights" discourse and the recognition of children's voices and their right to be heard has propelled a shift in ethical frameworks concerning children. This shift is dealing with important ethical issues such as the narrow conception of the best interests standard (BIS) and how it should be reconciled with the recognition of children as agents with their own views and interests (Cantwell, 2017; Carnevale, 2012).

The BIS is supposed to ensure that children derive the greatest benefits in proportion to burdens from all actions and services that are directed to them. It operates on the basis of children's inability to exercise their rights fully and independently, and physical/emotional limits on their ability to assert their interests. These limits require that surrogate actors hold the power to make decisions on their behalf (Brock \& Buchanan, 1989). Surrogate actors include all adults with a "duty of care" toward a child (e.g., teachers, health professionals, community workers).

Notwithstanding the importance of BIS, there are significant concerns about how it should be understood 
(Kopelman, 2010; Salter, 2012; Sayeed, 2010). The limited conception of this standard risks framing children as moral "objects" whose interests are determined by adults (Lee, 2001; Wall, 2010).

On the other hand, advancements in the recognition of children's voices and agency have been well underway in the field of childhood studies. Regarding children as social "actors" propelled the development of the concept of agency in childhood and the recognition of children as moral "subjects" (Esser et al., 2016; Montreuil \& Carnevale, 2016). Esser et al. (2016) argued that agency is a dynamic and relational concept "produced in conjunction with a whole network of different human and non-human actors" (p. 9). Moral agency begins with and is shaped by children's engagement with the world around them. As moral beings, children are able to act deliberately in light of moral issues, actively reflect on their moral experiences, and shape the world around them based on these reflections and/or actions (Montreuil \& Carnevale, 2016). Through this operationalization of agency and moral agency, children participate in the construction of their social relations (e.g., son/daughter, students, friend, research participant) and form their own world of meanings (Pufall et al., 2003; Wall, 2010). Such meanings orient children's everyday experiences and are rooted in the social and relational context in which experiences take shape (Carnevale, 2016).

Adapting an earlier general definition by Hunt and Carnevale (2011), children's moral experiences are defined as a "(child's) sense that values he or she deem important are being realized or thwarted in everyday life. This includes a (child's) interpretations of a lived encounter, or a set of lived encounters, that fall on spectrums of rightwrong, good-bad or just-unjust" (p. 659). On a societal level, efforts to address childhood needs are shaped by social institutions such as education, child welfare, and law. Childhood socialization, moral education, protection, discipline, and cultural transmission are examples of social processes enacted within the aforementioned social institutions, making them ideal settings for studying children's moral experiences.

\section{The education context}

Educational institutions such as schools and preschools are an integral part of children's social lives. Schooling practices have evolved over time. Traditional classrooms are typically teacher-centered with children as passive "becomings" and at the receiving end of information, skills, and discipline (Lee, 2001). Modern classrooms, on the other hand, adopt increasingly child-centered approaches where children play more active roles in their learning and teachers break away from adultcentric authority to adopt the role of a facilitator of children's experiences in the classroom. These shifts are most evident in infant and primary education in affluent Western societies where free play and child-led activities are part of the educational practices. However, Lee (2001) argues an ambiguity remains in the way children are viewed in the context of education and that this evolution in schooling practices does not necessarily alter the view of children as "becomings," albeit now active learners.

Interactions between and among children and educators are constantly shaping the socio-moral atmosphere of modern educational settings. Children's agency may be enabled or thwarted by adult educators in different situations, and children may resist or negotiate institutional norms in ways that shape their everyday lives and the collective experiences of the children. Moreover, the classroom culture and behavioural expectations will influence how children interact with their educator and among themselves, how they resolve conflicts, and the extent to which they engage in negotiation (DeVries \& Zan, 1994; Nieme, 2016).

\section{Background to the pilot study}

In 2014, an interdisciplinary team of researchers led by Franco Carnevale launched the VOICE project (https:// www.mcgill.ca/voice/). The principal aim of this ongoing initiative is to advance interdisciplinary research and 
knowledge mobilization and thus address ethical concerns relating to childhood. The specific objectives of the research program are to (1) examine the moral experiences of children in situations involving a determination of their best interests and/or their engagement as moral agents; (2) investigate how children's best interests and moral agency are conceived by four key social institutions (child welfare, education, law, psychology); (3) identify significant concerns that emerge within and between children's moral experiences and institutional practices; and (4) highlight priorities for the development of norms, policies, practice standards, research, and educational programs for child-related professions and develop materials to respond to these recommendations, based on the findings of this research.

\section{Theoretical framework}

This research draws on a sociological and an ethical framework. The former is James and Prout's (2015) new sociology of childhood. This framework challenges the dominant developmental conception of childhood and promotes understanding childhood as a social construction where children are seen as "active in the construction and determination of their own social lives, the lives of those around them, and of the societies in which they live" (p. 7).

The latter framework, known as the VOICE childhood ethics (CE) framework, is a subspecialized field of inquiry within childhood studies developed by Franco Carnevale. The framework focuses on developing knowledge and practices regarding children's moral experiences and advancing understanding and recognition of children's experiences, interests / best interests, aspirations, voices, and agency (Carnevale, 2016). CE is particularly concerned with dominant binary moral conceptions of young people as either incapable and in need of protection of their best interests or as quasi-autonomous capable agents. CE acknowledges complex intersections between these two polar opposites. As a field of inquiry, it recognizes that all children have voices and a right and interest to be heard (with agential capacities and aspirations), as well as vulnerabilities and a right to be protected in light of their best interests.

CE seeks to better understand these dimensions of children's moral lives by developing methodological approaches that can optimize these research aims. The focus on moral experience entails interpretive research approaches, such as ethnography, examining how children construct, defend, or negotiate their agential capacities and how the social context of institutions, like schools, shapes their experiences of right/wrong, good/bad, just/unjust.

\section{Aim of pilot study}

This pilot study preceded larger-scale data collection in a broader, ongoing research project with a central focus on critiquing the BIS and moral agency by examining the moral experiences of children in different social settings. The aim of this pilot study was to develop and refine data collection and analysis methods to examine the moral experiences of children in the context of education. Two data collection methods, ethnographic observations and individual interviews, were used. Analysis of these diverse sets of pilot data aimed to (a) demonstrate potential results that could be generated and (b) foster an examination of methodological challenges involved in researching moral experiences of children with these methods.

\section{Methodology}

This pilot study was conducted in a community centre that operated a preschool facility and ran an afterschool program for school-aged children. We piloted ethnographic participant observation (PO) in the preschool and conducted interviews with primary-school children in the afterschool program. 
PO involves the immersion of the researcher in the social world of participants through participating in and observing what goes on in everyday social settings (Spradley, 2016). This approach allows for data to be collected in a natural and flexible manner, while providing the time and space for building relationships between the researcher and the child (Morrow \& Richards, 1996). In contrast, interviews are a useful tool to elicit children's own accounts of their experiences and perspectives. Since the aim was to pilot test these methods of data collection, we assigned one data collection method to each group. We did not conduct PO in the afterschool program given the low and inconsistent rate of attendance.

\section{Child-adapted strategies}

Given the shift toward seeking agential views of children, methodological considerations have been raised in the literature concerning doing research "with" children. These include addressing the power differential between adults and children, listening "authentically" to the voices of children to better access their worlds, and using childadapted research methods (Carnevale, 2012; Christensen, 2004; Mayeza, 2017; Punch, 2002). Mandell (1988) proposes adopting the "least-adult" role in PO to help the researcher gain entry into the world of children. She defines being least-adult as a "role which suspends adult notions of cognitive, social, and intellectual superiority and minimizes physical differences by advocating that adult researchers closely follow children's ways and interact with children within their perspectives" (p. 464). Consequently, children begin to relate to the researcher more like a child and less like an authority-figure. The researcher then develops friendly and playful connections with children leading to more child-centered relationships (Mayeza, 2017). However, this approach has been criticized for oversimplifying power issues and the complex representations of adult roles and adulthood (Christensen, 2004). For PO in this research, we adopted Christensen's recommended approach of continually balancing the recognition of the researcher as an "adult" while attempting to avoid connotations and practices associated with "adulthood" and adult roles (such as parent or teacher). This approach supports children in implementing their own "rules" or "practices."

Other increasingly used strategies include activities such as drawing, photography, and diaries (Ford \& Campbell, 2018; Punch, 2002). We gave our school-aged participants the option to fill a journal/diary that was provided to them after the first interview. They were told they could use it to keep a record (in writing or drawing) of any incident or event that took place in school (e.g., something good/bad, fair/unfair, right/wrong).

\section{Research process}

Research ethics approval was obtained from McGill University's Research Ethics Board. Once access was granted by the community centre, an administrator coordinated meetings between the researcher and educators from both the preschool and the afterschool team. The purpose of the meetings was to describe the project and seek the educators' help in distributing consent and assent forms. A researcher (NM) was available on preannounced dates to answer parents' questions or queries.

In the preschool section, seventeen signed parental consent forms were returned to the researcher. The ages of the children ranged between 2.5 and 5 years. There were two classrooms and the children were grouped according to age (2-3 years old and 4-5 years old respectively). The pilot PO lasted two weeks and was preceded by two introductory visits. PO time was divided between the two classrooms depending on their schedule and activities. NM observed and directly engaged with children in the classrooms and in other spaces in the centre where they had activities (i.e., library, gym, or outdoors). The researcher tried to orient some interactions with guiding questions and recorded data in field notes. An example of the guiding questions is, How do children demonstrate 
moral agency in situations when adults seem to be determining for the children what is in the child's best interests?

Despite the common educational program used in both classes, each classroom had its own characteristics influenced by the approach of the educator. The relative balance of researcher's participation and observation activities varied depending on the nature and structure of activities, interests of the children, and classroom "rules." We introduce two vignettes at the beginning of the results section to illustrate the characteristics of the observed classrooms.

In the afterschool program, only three parental consent and child assent forms were signed and returned. All three participants were 9-year-old boys. They all attended the same public primary school. Each participant was interviewed three times, with a one- to two-week period between interviews. Meetings were scheduled based on the children's availabilities and preferences. Open-ended questions were used to initiate the conversation and were paraphrased from guiding questions such as: Describe a situation where you were faced with deciding what was the right or fair thing to do. What seemed right/wrong, good/bad, or fair/unfair?; Who was involved? What did you think/ do? How did you feel? What happened? iTunes gift cards (\$20 each) were given as a form of compensation at the end of the research.

\section{Analysis}

PO data consisted of handwritten field notes, informal conversations, and critical reflections. NM regularly added interpretive comments to the field notes, making contextual links to help illustrate the observed interactions and describing self-reflections in different situations. Raw PO data was synthesized into a narrative format (i.e., reflective comments were built into the recorded observations and interactions, creating a narrative text to facilitate reading). Interviews with the school-aged children were transcribed verbatim. Documents were regularly shared with the coauthor for discussion of findings and interpretations. Although we did not use a coding guide during the inductive coding process (Rivas, 2012), our data analysis was influenced by the guiding theoretical frameworks. An iterative process of coding, categorizing, and constant comparison (Memon, Umrani, \& Pathan, 2017) led to the development of the illustrative themes presented below.

\section{Results}

The following is an overview of the data and analysis that were generated from pilot PO and individual interviews. The aim here was to illustrate the types of findings that can be obtained when researching moral experiences of young children. We also highlighted data that reflected methodological issues concerning doing research with children. All names have been changed to maintain anonymity.

\section{PO data}

Institutional context: Curriculum. The educational curriculum adopted by the institution had a "child-led" focus. According to the three educators (including one substitute), the curriculum encouraged child-led activities and adapting lessons to the children's curiosities and interests. Every educator attended a two-day training course on this approach. However, one educator described the curricular training as insufficient and mostly focused on communication with parents (e.g., communicating program information and newsletters).

The activities we observed were aligned with the aforementioned curriculum goals. For example, a newsletter that was posted to the parents in classroom B explained the source of inspiration for an art project completed by the children and displayed on the classroom walls. The educator had noticed the children's interest in a particular 
animal when she was reading a story from a picture book, so she developed an art project around it. The art project also served an educational goal: teaching children the motor skill of handling scissors.

Institutional context: Classrooms. The following vignettes are intended to help the reader visualize the researcher's view of the classrooms.

Vignette 1, Classroom A: 4- to 5-year-old children. This morning, there were seven children and three adults: one educator and two volunteers (this classroom welcomes community service volunteers). It was "free play" time for the children, and the educator was completing some documents in the corner. One volunteer was playing with a child, while the other was sitting on a small chair looking tired and uninterested. Some children were building a train track and two were playing pretend cooking. A child was getting into a car-race driver costume and asked the researcher if she wanted to help him repair tires. They carried their imaginary tires to the corner and pretended to pump air into them. "Wait! If we push one more time, the tire will pop!" the researcher said. The child smiled mischievously and pretended to push harder. The researcher made a popping sound, "Boom!” The child started laughing and asked that they repeat the scene. Later, the educator stood by the door and turned the lights off. He chanted a few words indicating that it was time for a new activity (snack time). The children abruptly stopped what they were doing and rushed to their cubbies to bring the lunch boxes.

Vignette 2, Classroom B: 2- to 3-year-old children. Mornings started with a free-play period in this class also. There were no volunteers here. The educator was preparing playdough as an optional activity for the children. She told the researcher it was homemade playdough that she had prepared herself. There were organized activity stations for the children to choose from (painting and playdough, book corner, toy corner). There was an uncovered clock on the wall with a pink dot-shaped sticker on one arm and a blue flower-shaped sticker on the other. Later, the educator made a distinctive sound: "Eyes on me everybody!" Once everyone was looking at her, she pointed to the clock and said, "You see where the pink dot is? When the pink dot reaches the blue flower, it will be cleanup time. Do you know why? We're going to see Emma! That means we have what today?" Some children responded in unison: "Library!" As the specified time approached, the educator repeated her instruction to look at the clock. "Is the pink dot at the blue flower?" A couple of children answered, "No, not yet." "That's right," she responded, "but it's almost time."

The two classrooms described above had different social atmospheres. Despite the similar schedules (periods of free play, gym time, or library time), the dynamics and social order varied. Classroom A appeared more relaxed in terms of structure. The children were more forthcoming with the adults in the room, and there was more child-adult negotiation. Also, transitions between activities were sometimes ad hoc and rushed. Some children occasionally responded by objecting and refusing to cooperate. On the other hand, classroom B was evidently orderly and neat. The daily schedule typically ran in a smooth, predictable manner, and the educator always gave the children multiple cues prior to switching activities. There was a high sense of self-efficacy and confidence among most children in this classroom, despite their younger age.

PO themes. Through observation of interactions, we identified how children acted and reacted in different situations and how their agency and moral agency shaped and were being shaped by the educational context of the preschool and the other social actors involved. The following themes point out how children actively constructed their day with the support of educators, how they voiced their resistance to control, and their interactions or reactions that reflected a sense of moral agency.

Children's choices valued. Some learning activities in the two classrooms were child led, as encouraged by the institutional curriculum. Additionally, there were opportunities for the children to voice their own interests and 
choose an activity, albeit within a structured schedule. For example, during free play in classroom B, the educator was leading a playdough station and a painting activity. She invited the children to join her. Two children chose to participate, while James said "No, thanks" and continued to play with blocks. The educator nodded and said "Okay." In another example, the educator in classroom A turned off the lights to signal transition to snack time. Then he added, "It's snack time, so if you would like to eat you should..." "Clean up five things!" the children replied. "And if you don't want to eat, you..." "Keep on playing!" responded the children. One girl continued playing while the rest cleaned up their toys. These examples demonstrate instances where educators facilitated or encouraged children's agential voice. Sometimes, however, educators resorted to using their power without attention to individual children's voices, as we describe in the paragraph on moral agency below.

Children challenging authority. In both classrooms, some children tried to negotiate adult authority or challenge rules. When the educator told Elise to put the doll away for cleanup time- "Counting till five ... will take it away if I reach five!"-Elise held on to the doll until the last count, then put it away. NM frequently noted such interactions in both classrooms. Despite reminders and countdowns, some children repeatedly expressed objection by resisting or ignoring warnings and pushing boundaries to the limit. Sometimes, when they were able to break a rule, children appeared thrilled by the notion of resisting authority: One day during lunch, Sarah and Sandy sat together at the far end of the classroom. They knew they were not allowed to share lunchbox foods (a rule that the educator repeatedly stated), but on that day they realized that by sitting at the farthest table in the classroom, they could discreetly exchange foods without being noticed. They were aware they were breaking a rule (they exchanged food quietly and kept an eye on the educator). The girls managed to taste each other's food and they giggled triumphantly. They repeated this on two other occasions, until they were caught by the educator. The educator restated the rule but did not engage with the children nor give reasons for this rule.

Grown-up glory and moral agency. When the children interacted with each other, they enacted being older or bigger as a sign of independence and power. It was good to be big and bad to be small, or worse, a "baby." Being labelled a baby was always ill received among the children. During a pretend-play activity in classroom B, Elise (who was physically the smallest) took charge of assigning roles to the pretend family she was forming with her friends. She said to Dave, "You will be sister." Dave did not object, but soon after there was a conflict and Elise spoke loudly and firmly: "I am a big girl! And I can do anything I want since I am a big girl (she put her arms up in the air to appear bigger). You're a tiny baby!" Dave became evidently upset and responded tearfully: "I am not a tiny baby! You said I am a sister."

Another excerpt from the PO data illustrated this theme:

Liam (5 years old, while lining up to go to the library): "Are you a teacher?"

Researcher: "Yes I am. I teach big kids, though."

Liam: "But big kids don't need to be teached because they're big already."

We also noted instances where the children expressed their sense of right or wrong. In one example, while the researcher was reading a picturebook titled Little Dino Don't Yell to some students in classroom A, she stopped at a page with a picture of a little dinosaur yelling at his father. The children were looking in disapproval. "Is this okay?" she asked. The children shook their heads negatively. "Why?" she asked. "Because it hurts someone's feelings," one of them answered. The child here did not make a specific reference to the father in the story, and when the researcher probed a little, asking, "How about when you talk to your friends or siblings?" the child affirmed, "It's not okay to yell at anyone!" 
Sometimes, however, expressions of agency were thwarted due to educators' inability to balance being attentive to children's voices with exercising power. For example, when the substitute teacher asked children to clean up their toys in preparation for lunch ("The train tracks can stay out, but anything we could trip on should be cleaned up!") one child expressed confusion as he tried to make a judgment about whether or not the train tracks could be left out. The educator did not pay attention or listen and just wanted him to hurry. Such instances came in stark contrast to the examples above where children's voices were encouraged.

Tension between moral agency and best interests. An interesting adult-child interplay on best interests and agency emerged during PO. In one example, during snack time, the educator of classroom B was encouraging the children to eat their "growing" foods (e.g., fruits and vegetables) before eating less healthy snacks, such as energy bars or cookies (children come with home-prepared lunch boxes). This educator was keen on teaching healthy eating habits. Bob picked his energy bar, saying, "I want to eat this." The educator peeked into his lunch box and said, "No, you have strawberries. Remember, growing foods first." "I want to eat my bar, I don't want strawberries," Bob repeated a couple of times, but the educator gently insisted on the rule. Bob eventually put down the energy bar and started eating strawberries. He soon asked if he could stop, but the educator encouraged him to have a few more. After he had eaten a few more (seemingly reluctantly but not complaining), the educator told him he could have his energy bar. Surprisingly, Bob responded, "I don't want the bar anymore, I don't feel like it" and he happily ate a couple more strawberries before packing away his lunch box.

This situation highlights how, when a child's well-being is concerned, adult interference could be morally justified when coupled with a willingness to give reasons for rules and to refrain from arbitrary coercion. Yet it also raises the question, to what extent can acting in the best interest of the child be adapted to their preferences here and now?

\section{Interview data}

In the interviews, we asked direct questions about what it means to be good or bad, fair or unfair. Two out of the three interviewed boys in the afterschool program revealed quite distinctive dispositions. Alex was quiet and waited for the researcher to initiate conversation. He sat still and appeared nervous at the beginning of each interview. Mike, on the other hand, did not appear nervous but was easily distracted and kept moving about in his chair. None of the participants kept journal entries, and they seemed to forget about their journals between interviews.

Themes. Meaning of moral values. When asked what "being good" meant to them, the boys described this notion in different ways. Alex spoke about being good within the context of interpersonal relationships, referring to good actions and good deeds. He then elaborated on the boundaries of doing good and being helpful:

[Being good is] helping someone, like if they get hurt.... There was like a person today at recess, he like helped someone but he didn't actually ask if they were okay, like ask, "Do you need some help?" When they [students] were having trouble with a question, she [his teacher] came over to them and gave them a little hint, like on what the first syllable is, and they got it ... like not too helpful but like helpful enough so that they get it.

On the other hand, Mike described "being good" in the context of hierarchical relations between adults and children, where being good was equated with obedience and following the rules:

[Being good is] listening, not getting in trouble ... and no um, um hurting others.... Listening is just hearing what the teacher says because in tests you have to actually listen, because if you don't, you not know anything about the test. 
Researcher: How do kids "get in trouble"?

Mike: Pushing, um bullying ... um not listening. And not listening to a teacher.... I was playing with my friends on the mountain and I was not supposed to. The teachers watch from far away and um they were not paying attention so um, like my friend and me went on the mountain and every time the teacher came, we went down, then um one time, we both got in trouble.... I feel um bad for myself ... and kind of annoyed ... annoyed that I got caught! Because I don't like getting caught. If you get caught, you're doomed, you can't run away! If you run away, you get in more trouble. If my friends weren't at school, I'll be the um, I would be a real good listener ... with my friends I go crazy, out of my mind!

Similarly, when asked what "fairness / being fair" meant to them, our participants responded differently. Alex described fairness in the context of interpersonal situations:

Letting someone play with you [is being fair] ... teachers who choose hands [are fair], if someone always raises their hands, she doesn't always pick them.... Also if you're working in a team and you both have the same answers, she doesn't give you like an A and give the other person like a B, that's not fair.... It's unfair when you always make rules that will help you but not other people.... I was like playing tag and someone kept touching me ... we had a time-out and my friend asked him to play fairly and to touch everyone else too.... I feel good, it's like they're standing up for me. I didn't want to say anything because I thought he was gonna get mad at me.

Then he explained how he makes moral judgments, relating to how the process works for adults, whom he described as good at handling tough situations:

I usually think in my head before, like if I do this, for example, like the tag example, if I keep on touching someone, how would they react, or how would I react if they do it to me? I think that they (grownups) do it good because they always think a lot before. I usually think in like one way, or two ways, to figure like bad and good, but grownups will think in like four ways about like bad and good. They have a bigger brain than us and they've learnt more.

Mike, on the other hand, did not elaborate on fairness as a moral concept but redirected the conversation toward his perception of adult authority.

[To be] fair is to give equal amounts, like ... when you split up a cake ... I don't know what it means [for a teacher to be fair]. My teacher is strict and funny in the same time.... My science teacher, he always yells, he's a real strict man. I don't know why but he was always strict ... just like never smiles. I feel bad for him, like why does he [not smile], like I really want to figure out why ... um maybe people when he was a little kid, um, were annoying him.... People be strict to me if I do like one tiny mistake!

The above excerpts highlight the different meanings children attach to moral concepts based on their interactions with other children and the adults in their lives. For example, being good was on one hand associated with being helpful and considerate, and on the other hand, it was explained in terms of discipline and abiding by rules. Although we did not observe these children in context, they engaged differently with the topic of moral experiences. Such findings indicate the uniqueness of children's experiences within the same educational institution.

Indeed, other factors besides lived experiences may influence the interview data, including being interviewed by an adult (representing an authority figure) and the character disposition of each child.

\section{Building rapport and power dynamics}

We examined relational engagement with child-participants in our operationalization of this research, which we 
frame here as "rapport." During PO, two factors facilitated building rapport with the young children. The first was contextual: one group of children was accustomed to having adult volunteers in the classroom who helped the educator with daily activities; therefore, NM noted that her integration into this class was easier than anticipated. Second, NM found that by genuinely participating in children's play and following their "rules," she was able to foster a sense of trust with the children, who responded by inviting her to play with them.

In one example, Sarah and Elsa were playing inside a pretend home they built using mini-furniture toys. NM asked if she could join them, but the girls refused and told her she was "too big." NM suggested they could use a pretend magic wand to make her smaller. The girls agreed happily, and NM pretended to shrink as one of the girls waved the pretend wand at her. Later, before stepping out of the pretend home, Sarah said, "Wait!" She held up her arm pretending to wave the magic-wand and said, "Now you're big again!"

In a similar example, while the children were lining up for gym time, the following conversation took place:

Researcher: May I line up here with you?

Mike: No.

Researcher: Why?

Mike: You're not a kid!

Researcher: Hmm, what if I pretend that I am one? (kneeled on the floor to match his height) How about now?

Mike (smiling): Yes, now you're the same size.

The other kids were all smiling in approval.

In both examples, the young children displayed agency in their interactions, setting rules for belonging to their world. These two instances highlight the value of reducing children's perception of adult power as a way to gain entry into their worlds.

On the other hand, interviews required different strategies for building rapport. For example, the institution's policy stated that a child could not be alone with an adult in any of the rooms/spaces within the centre. Thus, interviews had to be conducted in an open space, which meant that (a) the child had limited choice in terms of where the interview would take place, and (b) there were constant interruptions and distractions. NM tried to mitigate this barrier by asking the child to decide on the day and time of the interview and to select one of the permissible space options. On one occasion, despite having decided on the time and day, one participant appeared reluctant to have the interview as scheduled. Although NM had made the trip specifically for that interview, she asked the child if he did not feel ready for it and assured him they could reschedule. Indeed, the child immediately appeared more relaxed and asked to reschedule.

During the interviews, the researcher noted certain elements that she perceived as helpful in terms of rapport building, such as having general conversations, sharing her personal interests, and, where possible, avoiding sitting across from the child in a standard desk-interview position (one interview was conducted while sitting on the floor side by side, allowing the child to move freely and reducing eye contact with the researcher). 


\section{Discussion}

The aim of this pilot study was to develop and refine data collection and analysis methods for examining the moral experiences of children. The context for this study was an educational setting where moral experiences of children shape and are shaped by regulated socialization processes. In this section, we discuss the limitations and implications of our data collection methods, as well as tensions between "agency" and "best interests."

\section{Data collection methods}

In terms of methods, we found that $\mathrm{PO}$ allowed for collecting data that is enriched by observing the context within which children's actions and interactions took place. Indeed, ethnographic approaches, such as PO, are well suited for exploring the experiences of children in their social environments (Carnevale et al., 2008). We also believe that the personal characteristics of the researcher contributed to how much she was able to employ certain rapportbuilding strategies. NM enjoyed playing with children. The combination of her affinity for young children and her personal experiences as a mother and volunteer teacher in primary schools may have facilitated her integration and helped reduce the power differential.

In this pilot study, we did not interview the children in the preschool classrooms, considering PO a better-adapted data collection method for this group of children (although some informal conversation took place with the children throughout the PO). We anticipate that a combination of PO and interviews (formal or informal) could generate the richest possible insights into the moral experiences of young children.

Interviews remain an important method to elicit children's own voices and opinions as opposed to adult interpretations of observed interactions (Eder \& Fingerson, 2002). This said, establishing rapport with the school-aged children in this study was more difficult due to some contextual barriers and institutional policy. Familiarization with the setting in which the study will take place might help researchers adapt their methods to maximize outcomes. Moreover, the nature of the interview (questions and answers) represents a classic classroom model (initiation-response-feedback), which could emphasize the power differential. Unequal power between the adult researcher and the child stems from evident differences like age and status. A child who views the adult researcher as an authority figure might feel obliged to respond or act in a certain manner, especially within certain contexts (such as schools). To improve on the conventional model, NM used various strategies that were helpful, to some extent.

Methodologically speaking, multiple interviews over time and the introduction of journals with the older children were intended to facilitate relationship building and help the researcher relate to the children's experiences. The latter did not succeed, possibly due to the children's lack of familiarity with journalling or a lack of interest/ motivation. The three children who agreed to be interviewed happened to all be boys. We imagine that diverse gender perspectives could enrich the types of data that can be generated regarding moral experiences, although we were unable to explore this dimension with our pilot study sample.

\section{Reconciling "agency" and "best interests"}

Tensions between recognizing children's agency and protecting their best interests are a core focus in childhood ethics (CE). Within the CE framework, agency and best interests are reconcilable, although at times protection may require doing things that counter children's expressed preferences (e.g., eating healthy foods, holding hands to cross the street) These protective actions should be adapted, to the greatest extent possible, to the child's preferences.

Recognizing agency does not mean forgoing guidance. However, what strategies can help maintain a balance between best interests and agency? If we take a closer look at the description of the classrooms observed in this 
study, we may find that in classroom B, the educator's operationalization of resources and activities in a consistent and orderly manner may have helped her maintain a balance between protecting the children's best interests and recognizing their agency. When this educator was trying to instill healthy eating habits, she gently insisted that the child eat his fruit first, reminding him that "growing" foods help him grow up healthy and strong. She also did not forsake the child's desire to eat his snack and reminded him that he could eat his favourite bar once he had eaten a certain amount of fruit. Sometimes adults use their power to get children to do what is convenient for them, or just inadvertently do not take them seriously. However, this educator consistently took the time to explain reasons for setting rules, just like she took the time to prepare children for transitions between activities.

Finally, the interview data we presented offers an example of the distinct experiences and perceptions of two boys from the same school. These examples highlight that, in the context of education, individualized assessments of a specific child's best interests should be maximally informed by that child's views and experiences. Within project VOICE, we are promoting the recognition of children's agency as inherent in protecting their best interestsseeing agential respect as a child's interest. Adults who have power over children and are indeed in a position to contribute to the child's well-being must refrain from using their power arbitrarily and combine it with willingness to engage with children and to let them know that they are heard.

\section{Conclusion}

Despite the limitations of a pilot study, we were able to show examples of several instances where children's agency and moral judgment could be examined. Even within the same institution, every child is unique and every educator contributes to shaping the dynamics of the classrooms based on their own character and approach. In terms of methods, researching the moral experiences of children requires a constant adaptation of what is methodologically feasible to the specific contexts within which children's actions and interactions take place. Researchers are encouraged to take adequate time to familiarize themselves with any given context and to consider the development and refinement of the research strategies as an ongoing process that is molded by the specific encounters with the children. 


\section{References}

Brock, D. W., \& Buchanan, A. (1989). Deciding for others: The ethics of surrogate decision making (pp. 197-99). Cambridge University Press.

Cantwell, N. (2017, January). Are "best interests" a pillar or a problem for implementing the human rights of children? In T. Liefaard \& J. Sloth-Nielsen (Eds.), The United Nations Convention on the Rights of the Child (pp. 61-72). Brill. https://doi. org/10.1163/9789004295056 006

Carnevale, F. A. (2016). Recognizing the voice of the child: Developing a new paradigm for childhood ethics. Bioética Complutensa, 26(20-25).

Carnevale, F. A. (2012). Listening authentically to youthful voices: A conception of the moral agency of children. In J. L. Storch, P. Rodney, \& R. Starzomski (Eds.), Toward a moral horizon: Nursing ethics for leadership and practice (2nd ed.; pp. 315-332). Pearson Education.

Carnevale, F. A., Macdonald, M. E., Bluebond-Langner, M., \& McKeever, P. (2008). Using participant observation in pediatric health care settings: Ethical challenges and solutions. Journal of Child Health Care, 12(1), 18-32. https://doi.org/10.1177/1367493507085616

Christensen, P. H. (2004). Children's participation in ethnographic research: Issues of power and representation. Children \& Society, 18(2), 165-176. https://doi.org/10.1002/CHI.823

DeVries, R., \& Zan, B. (1994). Moral classrooms, moral children: Creating a constructivist atmosphere in early education (Vol. 47). Teachers College Press.

Eder, D., \& Fingerson, L. (2002). Interviewing children and adolescents. In J. F. Gubrium \& J. A. Holstein (Eds.), Handbook of interview research: Context and method (pp. 181-203). SAGE.

Esser, F., Baader, M. S., Betz, T., \& Hungerland, B. (Eds.). (2016). Reconceptualising agency and childhood: New perspectives in childhood studies. Routledge.

Ford, K., \& Campbell, S. (2018). Being participatory through photo-based images. In I. T. Coyne \& B. Carter (Eds.), Being participatory: Researching with children and young people (pp. 127-146). Springer.

Hunt, M. R., \& Carnevale, F. A. (2011). Moral experience: A framework for bioethics research. Journal of Medical Ethics, 37(11), 658-662. https://doi.org/10.1136/jme.2010.039008

James, A., \& Prout, A. (Eds.). (2015). Constructing and reconstructing childhood: Contemporary issues in the sociological study of childhood (2nd ed.). Routledge.

Kopelman, L. M. (2010). Using the best-interests standard in treatment decisions for young children. Pediatric Bioethics, 22-37. https:// doi.org/10.1017/CBO9780511642388.004

Lee, N. (2001). Childhood and society: Growing up in an age of uncertainty. McGraw-Hill Education.

Mandell, N. (1988). The least-adult role in studying children. Journal of Contemporary Ethnography, 16(4), 433-467. https://doi. org/10.11770891241688164002

Montreuil, M., \& Carnevale, F. A. (2016). A concept analysis of children's agency within the health literature. Journal of Child Health Care, 20(4), 503-511. https://doi.org/10.11771367493515620914

Mayeza, E. (2017). Doing child-centered ethnography: Unravelling the complexities of reducing the perceptions of adult male power during fieldwork. International Journal of Qualitative Methods, 16(1). https://doi.org/10.1177/1609406917714162

Memon, S., Umrani, S., \& Pathan, H. (2017). Application of constant comparison method in social sciences: A useful technique to analyze interviews. Grassroots, 51(1) 152-165. https://sujo-old.usindh.edu.pk/index.php/Grassroots/article/viewFile/3253/2359

Morrow, V., \& Richards, M. (1996). The ethics of social research with children: An overview. Children and Society, 10(2), 90-105. https:// doi.org/10.1111/j.1099-0860.1996.tb00461.x 
Niemi, K. (2016). Moral beings and becomings: Children's moral practices in classroom peer interaction. Jyväskylä Studies in Education, Psychology, and Social Research, 549. https://jyx.jyu.fi/handle/123456789/48975

Pufall, P. B., Unsworth, R. P., Boykin, A. W., Allen, B., Singer, R., \& Hearst, A. (2003). Rethinking childhood. Rutgers University Press.

Punch, S. (2002). Research with children: The same or different from research with adults? Childhood, 9(3), 321-341. https://doi. org/10.11770907568202009003005

Rivas, C. (2012). Coding and analysing qualitative data. Researching Society and Culture, 3, 367-392. https://is.muni.cz/el/1423/jaro2017/ ESS401/um/Rivas_366-392.pdf

Salter, E. K. (2012). Deciding for a child: A comprehensive analysis of the best interest standard. Theoretical Medicine and Bioethics, 33(3), 179-198. https://link.springer.com/article/10.1007/s11017-012-9219-Z

Sayeed, S. A. (2010). The moral and legal status of children and parents. Pediatric Bioethics, 38-53. https://doi.org/10.1017/ CBO9780511642388.005

Spradley, J. P. (2016). Participant observation. Waveland Press.

Wall, J. (2010). Ethics in light of childhood. Georgetown University Press. 